\title{
Soy herpes no me operes por favor
}

\author{
I am herpes do not operate me please \\ Dra. Claudia Gutiérrez-Gómez,* Dr. Carlos Gargollo-Orvañanos,* \\ Dr. Francisco Javier López-Mendoza, ${ }^{\S}$ Dr. Francisco Emilio Ferreira-Aparicio ${ }^{\llbracket}$
}

Palabras clave: Panadizo herpético, virus herpes simple, mano.

Keywords: Herpetic whitlow, herpes simplex virus, hand.

\footnotetext{
* Cirujana Plástica y Reconstructiva, Hospital General «Dr. Manuel Gea González». Laboratorio Biotecnología del Centro Nacional de Quemados del Instituto Nacional de Rehabilitación «Luis Guillermo Ibarra Ibarra». ‡ Ortopedista, cirujano de mano, Hospital Ángeles Pedregal. Profesor titular del curso de Alta Especialidad de Cirugía de la Mano, Universidad La Salle.

$\S$ Cirujano plástico y reconstructivo, cirugía de la mano y microcirugía; Hospital Ángeles Pedregal.

^ Cirujano Plástico y Reconstructivo, Cirugía de la Mano. Centro Nacional de Quemados del Instituto Nacional de Rehabilitación «Luis Guillermo Ibarra Ibarra».
}

Ciudad de México.

Recibido:

25 julio 2020

Aceptado para publicar:

10 agosto 2020

\section{RESUMEN}

En la práctica clínica nos enfrentamos a diversas patologías que son atractivas de operar; sin embargo, debemos ser cuidadosos al hacer un interrogatorio y exploración física con la finalidad de no producir más daño o un tratamiento innecesario, éste es el caso de las infecciones por herpes simple en la mano. Presentamos dos casos clínicos ilustrativos de esta patología: el panadizo herpético y una infección en la palma de la mano con dos procedimientos quirúrgicos previos. El panadizo herpético se refiere a una infección cutánea dolorosa que afecta comúnmente la falange distal de los dedos y ocasionalmente los artejos. Se diferencia de un felón, ya que este último implica una infección supurativa del pulpejo; las vesículas virales pueden involucrar cualquier región anatómica de la mano. El diagnóstico es clínico y si es poco claro, se pueden incluir pruebas diagnósticas como cultivo viral, títulos séricos de anticuerpos, frotis para prueba de Tzanck y detección de antígenos en la muestra. La prueba más sensible es el cultivo viral, lo que permite tipificar el virus herpes simple 1 o 2 . El tratamiento es sintomático y consiste en inmovilización, elevación y analgesia. Se prefieren apósitos secos para disminuir la posibilidad de diseminar la enfermedad. Hay reportes de complicaciones por diagnósticos erróneos tratados con incisiones e intentos de drenaje. La administración oral de 200 mg de aciclovir tres o cuatro veces al día previene y disminuye de manera importante los porcentajes de recurrencia en casos de panadizo herpético y otras manifestaciones no genitales del virus herpes simple. La administración intravenosa está indicada ocasionalmente en pacientes inmunosuprimidos con infección diseminada por virus herpes simple, pero no se recomienda como rutina en pacientes inmunocompetentes. Consideramos importante el conocimiento de esta entidad como cirujanos plásticos, ya que el pensamiento inicial sería de drenaje al confundirlo con un felón y en estos casos, lejos de mejorar, empeorará el curso de la enfermedad.

\section{ABSTRACT}

In clinical practice we face various pathologies that would be attractive to operate; however, we must be careful when a careful interrogation and physical examination are performed in order not to produce more damage or unnecessary treatment, which is the case of herpes simplex infections in the hand. We present two clinical cases illustrative of this pathology: the herpetic baker and an infection in the palm of the hand with two previous surgical procedures. The herpetic baker refers to a painful skin infection that commonly affects the distal phalanx of the fingers and occasionally the toes. It differs from a felon in as much as the latter involves a suppurating infection of the pulp; viral vesicles can involve any anatomical region of the hand. The diagnosis is clinical and if it is unclear, diagnostic tests; such as: viral culture, serum antibody titers, smears for Tzanck test and detection of antigens in the sample can be included. The most sensitive test is viral culture, which allows the herpes simplex virus 1 or 2 to be typified. Treatment is symptomatic and consists of immobilization, elevation, and analgesia. Dry dressings are preferred to decrease the possibility of spreading the disease. There are reports of complications due to misdiagnoses treated with incisions and attempts of draining. Oral administration of Acyclovir $200 \mathrm{mg}$, three or four times a day prevents and significantly decreases the rates of recurrence in cases of herpetic whitlow and other nongenital manifestations of herpes simplex virus. Intravenous administration is occasionally suggested in immunosuppressed patients with a disseminated herpes simples virus infection, but it is not regularly recommended in immunocompetent patients. We consider the knowledge of this case important as plastic surgeons, since the first thought would be draining when confusing it with a felon and in that case, far from improving it, the course of the disease will worsen.

\footnotetext{
Citar como: Gutiérrez-Gómez C, Gargollo-Orvañanos C, López-Mendoza FJ, Ferreira-Aparicio FE. Soy herpes no me operes por favor. Cir Plast. 2020; 30 (2): 117-122. https://dx.doi.org/10.35366/97675
} 


\section{INTRODUCCIÓN}

E panadizo herpético se refiere a una infección cutánea dolorosa que afecta por lo regular la falange distal de los dedos y ocasionalmente los artejos, fue descrito en 1909 por Adamson y popularizado en 1959 por Stern. El panadizo herpético se diferencia de un felón, ya que este último implica una infección supurativa del pulpejo. Las vesículas virales pueden involucrar cualquier región anatómica de la mano. ${ }^{1}$ La lesión es causada por el virus herpes simple (VHS) tipo 1 o 2, clínicamente indistinguibles, ambos presentan crecimiento rápido y lesiones citolíticas y ambas llegan al tejido nervioso para mantenerse en un estado latente; son miembros de la familia Herpesviridae más grande que incluye varicela zoster, citomegalovirus, Epstein-Barr y virus herpes humano 6, 7 y $8 .^{1,2}$

Se contagia por contacto directo a través de membranas mucosas o epidermis con solución de continuidad. El ser humano es el único huésped natural conocido. El virus herpes simple tipo 1 causa gingivoestomatitis en niños y adultos. ${ }^{3}$ El virus herpes simple tipo 2 causa herpes genital y típicamente afecta adultos o adolescentes con vida sexual activa. El panadizo herpético en niños es causado casi exclusivamente por VHS 1 y en adultos puede ser causado por VHS1 o VHS2. La infección

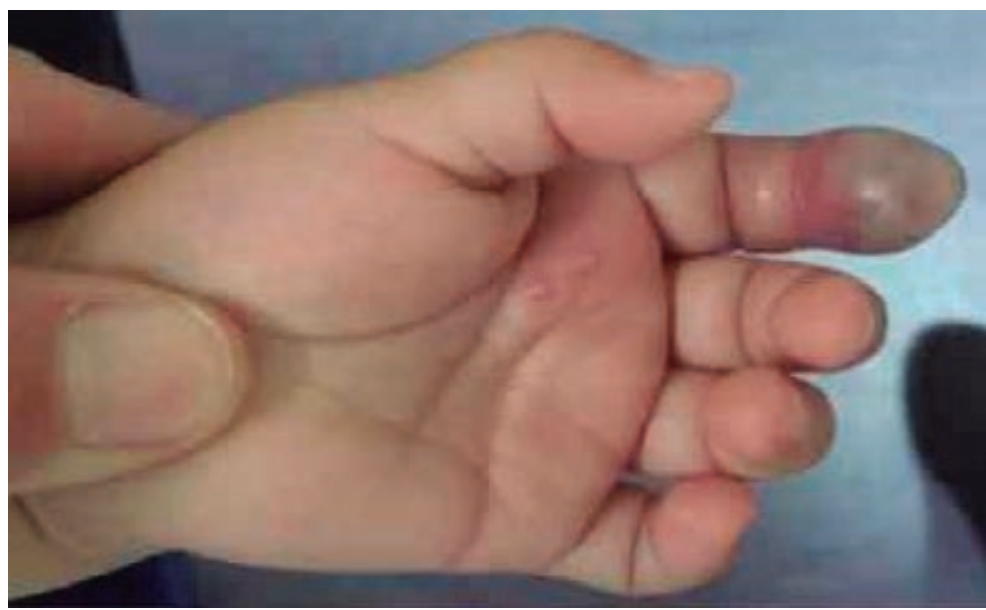

Figura 1: Vista anterior del panadizo herpético en el segundo dedo de la mano izquierda, con la presencia de dos vesículas en la palma de la mano a nivel del segundo metacarpiano. Se observa que las lesiones han coalecido en una mancha blanca que asemeja una colección purulenta y eritema en la base de la falange distal. por herpes en mano en niños se asocia a chuparse los dedos en portadores asintomáticos en saliva o en niños con manifestaciones orales del virus. ${ }^{3}$ Las lesiones herpéticas aparecen después de un periodo de incubación de dos a 20 días y se asocian a dolor punzante intenso. La presencia de fiebre o síntomas sistémicos es poco frecuente. Algunos pacientes reportan un pródromo de síntomas parecidos a una gripa antes de la formación de lesiones cutáneas. Puede presentar linfadenopatía regional, linfangitis, dolor en el dermatomo, o dolor irradiado a antebrazo proximal.

Habitualmente se presentan con una o un conjunto de vesículas provenientes de un dedo después de tres o cuatro días de irritación cutánea o después de trauma menor. ${ }^{1}$ Las vesículas son transparentes o amarillo claro y tienen una base eritematosa, con frecuencia se localizan en la falange distal del pulgar, índice o tercer dedo cerca de la uña. Pueden aparecer lesiones satélite como resultado de la erosión de las vesículas frescas durante las dos primeras semanas, lo que coincide con la ventana de actividad viral que dura un promedio de 12 días y es el periodo en el cual el paciente es más contagioso. Una vez que se detiene la propagación, cede el dolor y las lesiones existentes cambian de apariencia, el líquido claro de las vesículas se puede volver turbio o hemorrágico, el cual no debe confundirse con purulento. Las lesiones evolucionan a un periodo de ulceración y costra; eventualmente desprendimiento y caída de piel seca, descubriendo la epidermis cicatrizada por debajo. La historia natural del panadizo herpético es la resolución completa a las tres semanas. Algunas complicaciones raras consisten en viremia sistémica, infección ocular, distrofia de la uña, pérdida de la uña, cicatrices, hiperestesia localizada o hipoestesia, superinfección con estafilococo dorado. Después de la infección el virus queda en estado latente en el tejido nervioso y las infecciones recurrentes que se presentan entre 20 y $50 \%$ se disparan por enfermedad general, fiebre, exposición solar, menstruación y estados generadores psicológicos o fisiológicos de estrés. Puede haber síntomas prodrómicos dos a tres días antes como dolor quemante moderado y comezón o irritación en el sitio donde emergerá la lesión. Los procesos subsecuentes habitual- 


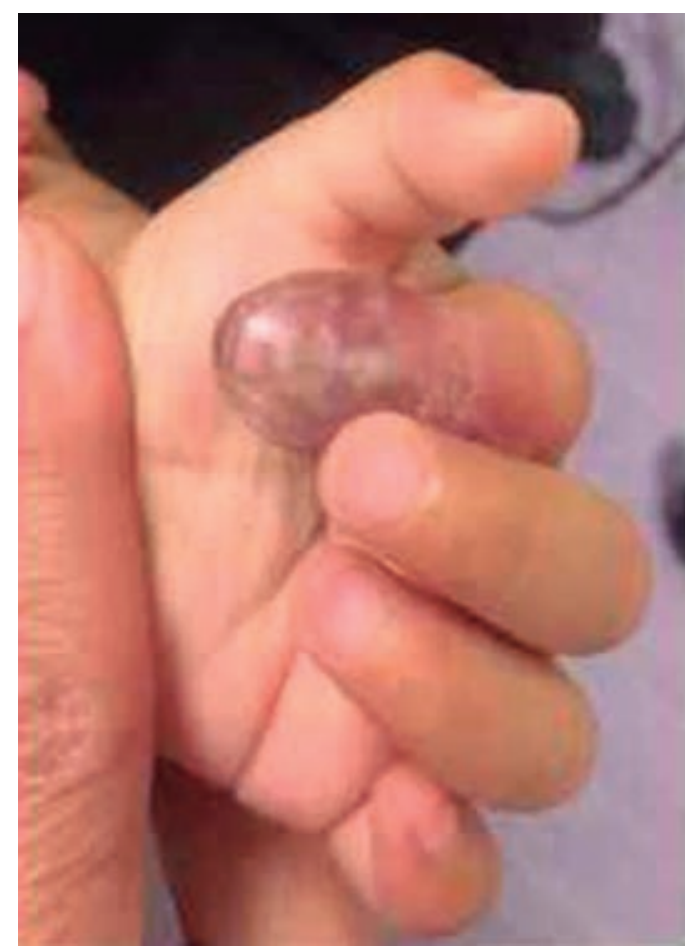

Figura 2: Vista dorsal del panadizo herpético en el segundo dedo de la mano izquierda, donde se aprecian manchas rojas y violáceas alternadas con manchas blanquecinas y eritema en la base de la falange distal.

mente son más cortos y de menor intensidad que la infección primaria.

El diagnóstico es clínico; si es poco claro, se pueden incluir pruebas diagnósticas como cultivo viral, títulos séricos de anticuerpos, frotis para prueba de Tzanck y detección de antígenos en la muestra. La prueba más sensible es el cultivo viral, lo que permite tipificar el virus VHS1 o VHS2.

\section{CASOS CLÍNICOS}

\section{Caso 1}

Niño de un año 11 meses de edad con inicio de padecimiento 11 días antes con fiebre y evacuaciones diarreicas y ulterior aparición de lesiones en mucosa bucal de tipo vesículas; manejado por facultativo con la administración de amikacina, paracetamol, ibuprofeno y nistatina. En el momento de su ingreso presentó lesiones en remisión en la boca, con algunas costras especialmente en labios, sin fiebre y con remisión del cuadro diarreico. La madre refirió que el niño acostumbraba chuparse el segundo dedo de la mano izquierda y que unos días antes de acudir al hospital presentaba aumento de volumen y coloración rojiza, la cual fue aumentando rápidamente y que a pesar de que ella misma puncionó el dedo, no notó mejoría. A la exploración física presentaba aumento de volumen en el pulpejo distal del segundo dedo de la mano izquierda, con coloración blanquecina en el pulpejo, eritema en la base de la falange distal y dos vesículas en la palma de la mano a nivel del segundo metacarpiano (Figuras 1 y 2). Se manejó con dicloxacilina ante la sospecha de una infección agregada, aciclovir 55 mg vía oral cada ocho horas, paracetamol $110 \mathrm{mg}$ v.o. cada ocho horas y se internó para vigilancia. No habiendo nuevas lesiones ni sitios de contagio agregados fue dado de alta cuatro días después y se indicó continuar con aciclovir seis días más. La dicloxacilina se suspendió a los dos días al descartar la infección bacteriana. Tres meses después del periodo agudo el dedo en la vista dorsal presenta la deformidad ungueal secundaria a caída espontánea de la uña, actualmente en crecimiento (Figuras 3 y 4 ).

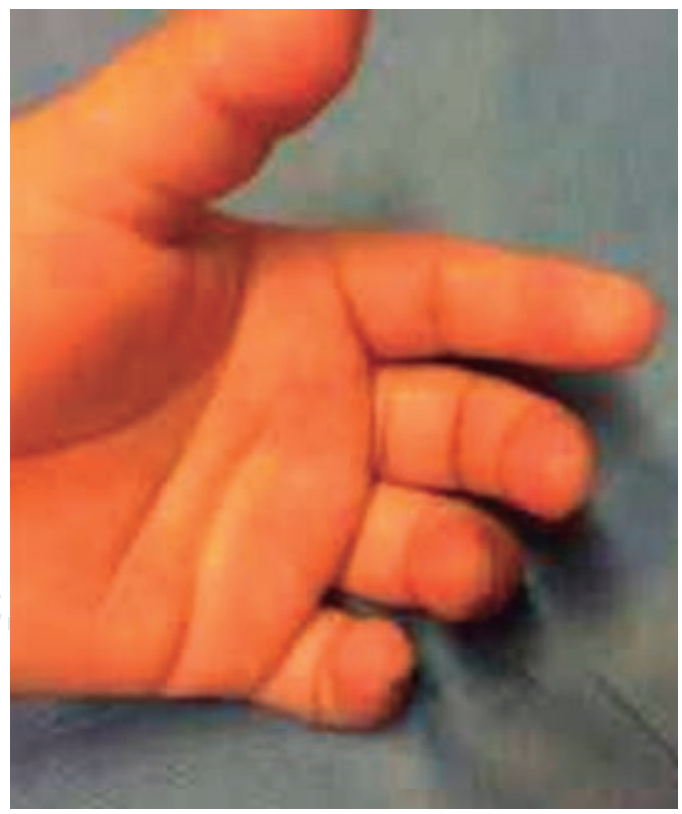

Figura 3: Vista palmar del dedo tres meses después del proceso agudo. 


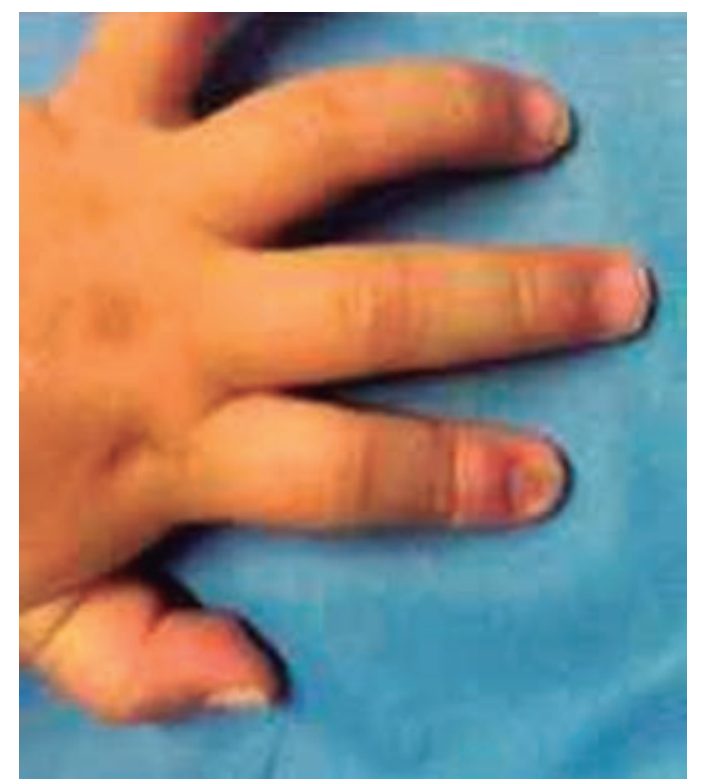

Figura 4: Vista dorsal tres meses después. Se aprecia deformidad de la uña que se desprendió después del proceso agudo y se encuentra en crecimiento.

\section{Caso 2}

Mujer de 41 años de edad que inició padecimiento 11 años antes, con la presencia de una ampolla dolorosa en la palma de la mano; refiere que la primera vez un familiar la puncionó apareciendo múltiples ampollas como en racimo de uvas. Posteriormente acudió con médico homeópata quien elaboró una vacuna logrando control aceptable durante siete años; sin embargo, al presentar recurrencia acudió a otra institución donde realizaron la primera resección quirúrgica con el diagnóstico histopatológico de probable nevo neuroide. Continuó con nuevas recidivas con duración de la lesión de dos semanas aproximadamente y remisión espontánea, tratando el dolor con paracetamol. Tres años después fue sometida de nuevo a tratamiento quirúrgico, con reporte histopatológico de hiperqueratosis, hipergranulosis, acantosis, inflamación crónica perivascular y sugirieron tomar una biopsia más profunda. Un año después la paciente se presentó con nueva recidiva de la lesión unos días antes, muy dolorosa; a la exploración física encontramos ampolla en la palma de la mano, cerca de la cicatriz previa, sumamente dolorosa, con trayecto eritematoso hacia el antebrazo, refiriendo dolor importante irradiado al antebrazo y solicitó su extirpación «urgente», ya que revisó en Internet y diagnosticó un tumor glomus. Se le explicó a la paciente la etiología viral de la enfermedad y la falta de utilidad de un tratamiento quirúrgico, ya que el diagnóstico más bien es citológico y una nueva cirugía causaría daño con el riesgo de contaminación por encontrarse en estado activo. Se le dio tratamiento con ibuprofeno 400 mg cada 12 horas por cinco días para controlar el dolor y la inflamación y aciclovir 200 g v.o. cada ocho horas por 10 días. La respuesta a dicho tratamiento acortó la evolución habitual de dos semanas a una semana, con remisión de la sintomatología 24 horas después de iniciado el tratamiento antiviral (Figuras 5 a 10).

\section{DISCUSIÓN}

Dada la etiología y el curso de los panadizos herpéticos la intervención quirúrgica es inne-

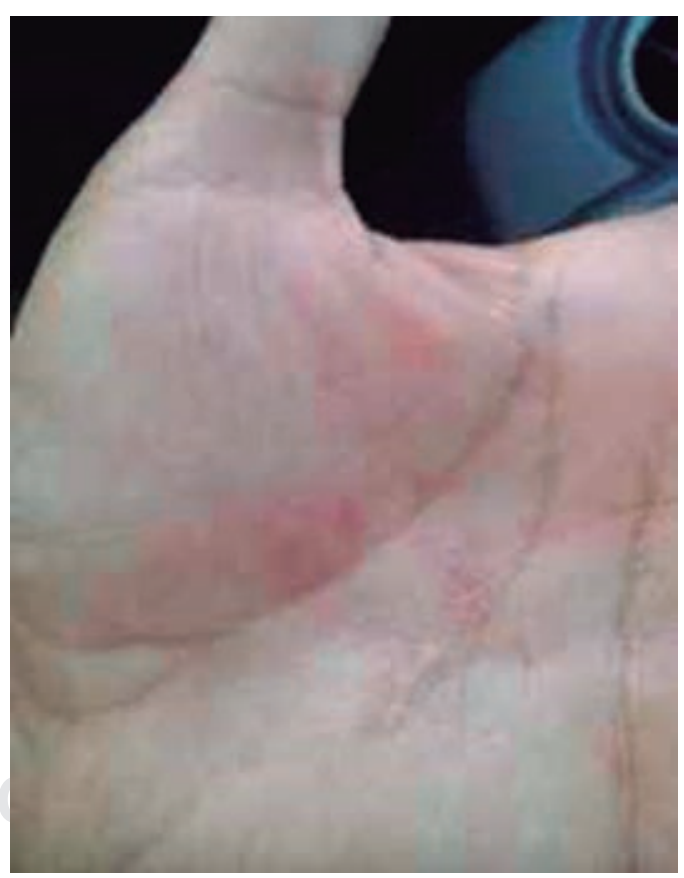

Figura 5: Mujer de 41 años de edad con antecedente de dos cirugías previas. La paciente presentó un día antes de la aparición de este eritema únicamente dolor en la palma de la mano (día 0). Día 1: se observa una pápula pequeña con eritema perilesional. 


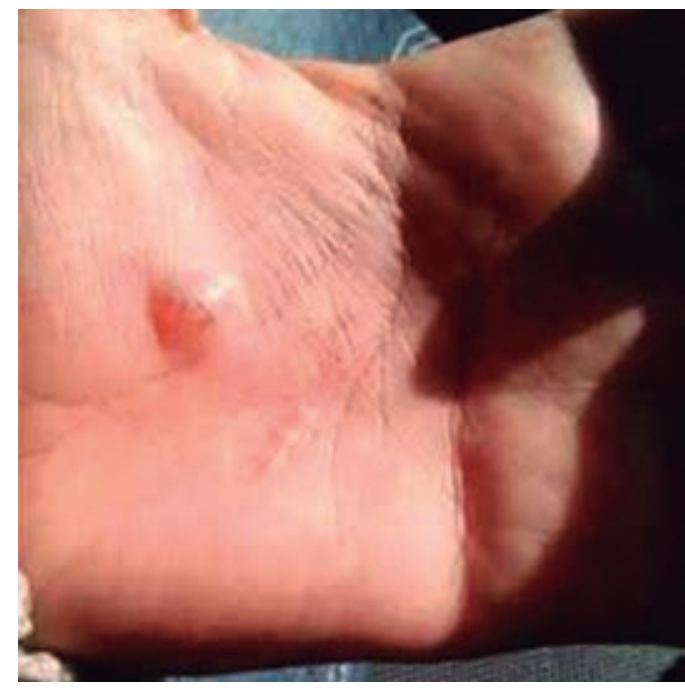

Figura 6: Día dos: se observa mayor eritema y una pápula más grande, con trayecto eritematoso curveado hacia el antebrazo, con dolor intenso irradiado al antebrazo que corresponde a la linfangitis reportada en casos severos.

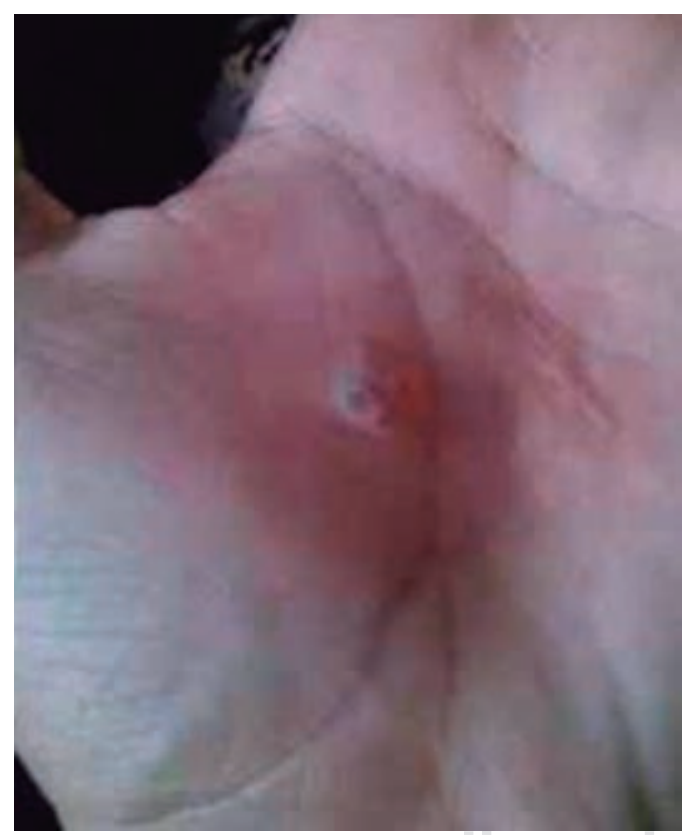

Figura 7: Día tres: se observa eritema perilesional y color blanquecino de la pápula con pequeñas vesículas amarillentas en su interior.

cesaria. El tratamiento es sintomático y consiste en inmovilización, elevación y analgesia. Se prefieren apósitos secos para disminuir la posi- bilidad de que la enfermedad se disemine. Hay reportes de complicaciones por diagnósticos erróneos tratados con incisiones e intentos de drenaje. Las incisiones no permitirán el drenaje, ya que el espacio profundo del pulpejo no está involucrado, a menos que haya sido violado iatrogénicamente. La infección bacteriana secundaria con más frecuencia por estafilococo puede resultar en amputación, infección sistémica y meningoencefalitis viral.

El uso de crema antiviral de aciclovir al 5\% acorta la duración de las lesiones en pacientes con herpes labial y genital, pero no ha sido es-

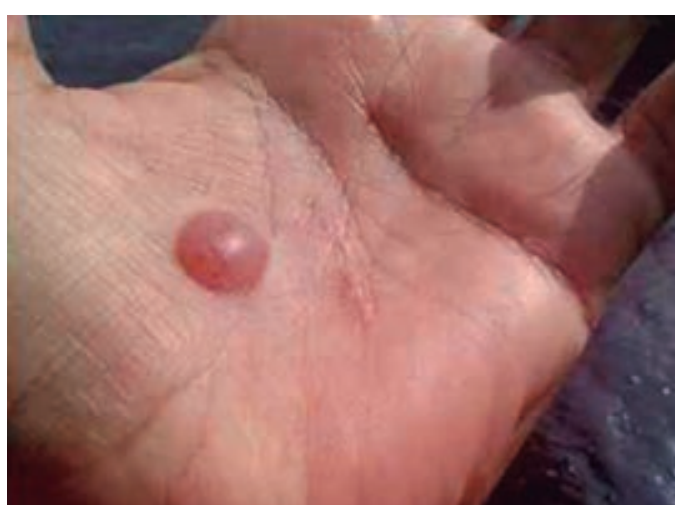

Figura 8: Día cinco: nótese la respuesta al tratamiento antiviral, el cual se inició el día cuatro de evolución, con ausencia de eritema perilesional, linfangitis y sintomatología dolorosa a las 24 horas de iniciado el tratamiento con aciclovir.

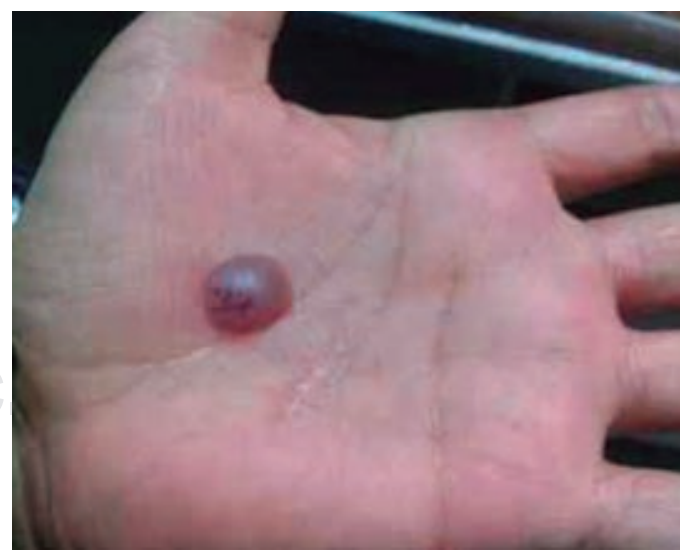

Figura 9: Día siete: se nota una coloración oscura de la pápula, lo que indica que el proceso va en franca remisión con disminución importante de la sintomatología. 


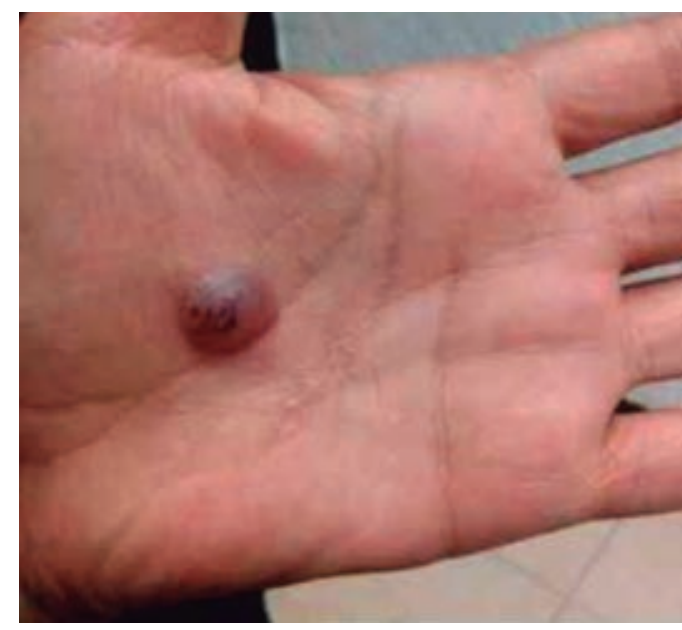

Figura 10: Día ocho: pápula asintomática.

tudiado su efecto específicamente en panadizos herpéticos. La administración oral de 200 mg de aciclovir tres o cuatro veces al día previene y disminuye de manera importante los porcentajes de recurrencia en casos de panadizo herpético y otras manifestaciones no genitales del VHS, el cual es bien tolerado y con pocos efectos secundarios y puede ser administrado hasta por dos años. Dicho efecto profiláctico está presente mientras se administra el medicamento y aplica sólo en individuos inmunocompetentes. Una dosis diaria total de 1,600 a 2,000 mg de aciclovir por vía oral ante la aparición de los pródromos puede acortar o prevenir la enfermedad.

\section{CONCLUSIONES}

Es importante conocer los antecedentes del paciente así como la presencia de lesiones concomitantes en otra parte del cuerpo como mucosa oral, además de las características clínicas, que si bien pueden confundirnos de entrada con un felón y se aplica un tratamiento quirúrgico, lejos de mejorar o salvar el dedo puede empeorar el curso clínico. Se debe prestar atención a la evolución para diagnosticar una infección bacteriana agregada.

Sin lugar a dudas, un diagnóstico oportuno permite un manejo apropiado con antivirales, con una remisión adecuada de la sintomatología y evita comorbilidades de un tratamiento quirúrgico innecesario.

\section{AGRADECIMIENTOS}

A Antonio Romero Rubio por su participación en la toma de fotografías clínicas.

\section{REFERENCIAS}

1. Rubright JH, Shafritz AB. The herpetic whitlow. J Hand Surg 2011; 36A: 340-342.

2. Wu I B, Schwartz R. Herpetic whitlow. Cutis 2007; 79: 193-196.

3. Patel R, Kumar H, More B, Patricolo M. Pediatric recurrent herpetic whitlow. BMJ Case Rep 2013; 010207. doi: 10.1136/bcr-2013-010207.

\author{
Correspondencia: \\ Dra. Claudia Gutiérrez Gómez \\ Puente de Piedra Núm. 150 T2 C 420, \\ Col. Toriello Guerra, 14050, \\ alcaldía Tlalpan, Ciudad de México, México. \\ E-mail: dra.claugg8@gmail.com
}

Conflicto de intereses: Los autores de este artículo no tienen conflicto de intereses que declarar. 